\title{
Diagnosis of Early Alzheimer's Disease: Clinical Practice in 2021
}

\author{
A.P. Porsteinsson ${ }^{1}$, R.S. Isaacson ${ }^{2}$, S. Knox ${ }^{3}$, M.N. Sabbagh ${ }^{4}$, I. Rubino ${ }^{5}$

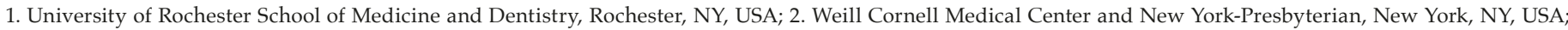 \\ 3. Biogen International GmbH, Baar, Switzerland; 4. Cleveland Clinic Lou Ruvo Center for Brain Health, Las Vegas, NV, USA; 5. Biogen Inc, Cambridge, MA, USA \\ Corresponding Author: Sean Knox, MBChB. Biogen International GmBH, Neuhofstrasse 30, 6340 Baar, Switzerland. Phone: +41413921976; Email: sean.knox@biogen.com
}

\begin{abstract}
Alzheimer's disease is a progressive, irreversible neurodegenerative disease impacting cognition, function, and behavior. Alzheimer's disease progresses along a continuum from preclinical disease, to mild cognitive and/or behavioral impairment and then Alzheimer's disease dementia. Recently, clinicians have been encouraged to diagnose Alzheimer's earlier, before patients have progressed to Alzheimer's disease dementia. The early and accurate detection of Alzheimer's disease-associated symptoms and underlying disease pathology by clinicians is fundamental for the screening, diagnosis, and subsequent management of Alzheimer's disease patients. It also enables patients and their caregivers to plan for the future and make appropriate lifestyle changes that could help maintain their quality of life for longer. Unfortunately, detecting earlystage Alzheimer's disease in clinical practice can be challenging and is hindered by several barriers including constraints on clinicians' time, difficulty accurately diagnosing Alzheimer's pathology, and that patients and healthcare providers often dismiss symptoms as part of the normal aging process. As the prevalence of this disease continues to grow, the current model for Alzheimer's disease diagnosis and patient management will need to evolve to integrate care across clinical disciplines and the disease continuum, beginning with primary care. This review summarizes the importance of establishing an early diagnosis of Alzheimer's disease, related practical 'how-to' guidance and considerations, and tools that can be used by healthcare providers throughout the diagnostic journey.
\end{abstract}

Key words: Alzheimer's disease, early diagnosis, diagnostic work-up.

\section{Introduction}

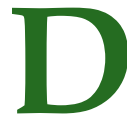
ementia is among the greatest global health crises of the 21st century. Currently, more than 50 million people are living with dementia worldwide (1), with this number estimated to triple to 152 million by 2050 as the world's population grows older (2). Alzheimer's disease (AD) is the most common cause of dementia and is thought to account for $60-80 \%$ of dementia cases (3). Currently, the total annual cost for $\mathrm{AD}$ and other dementias in the USA is $\$ 305$ billion and is predicted to increase to more than $\$ 1.1$ trillion by 2050 (3). This substantial economic burden includes not only healthcare and hospice support for patients with AD (3) but also lost productivity from patients and caregivers (4).

$\mathrm{AD}$ is a progressive, neurodegenerative disease Received February 22, 2021

Accepted for publication April 28, 2021 associated with cognitive, functional, and behavioral impairments, and characterized by two underlying pathological hallmarks: the progressive accumulation of extracellular amyloid beta $(\mathrm{A} \beta)$ plaques and intracellular neurofibrillary tangles (NFTs) (3). In AD, aggregated $\mathrm{A} \beta$ plaques are deposited within the brain as a result of either reduced $A \beta$ clearance or excessive production (5); plaque deposition typically occurs $\sim 20$ years before the onset of cognitive impairment $(6,7)$. NFTs are formed by the abnormal accumulation of hyperphosphorylated-tau protein (5); these can be detected 10-15 years before the onset of symptoms $(6,7)$.

AD follows a progressive disease continuum that extends from an asymptomatic phase with biomarker evidence of AD (preclinical AD), through minor cognitive (mild cognitive impairment [MCI]) and/or neurobehavioral (mild behavioral impairment [MBI]) changes to, ultimately, AD dementia. A number of staging systems have been developed to categorize AD across this continuum (7-9). While these systems vary in terms of how each stage is defined, all encompass the presence/ absence of pathologic $A \beta$ and NFTs, as well as deficits in cognition, function, and behavior (7-9). As a result, subtle but important differences exist in the nomenclature for each stage of $\mathrm{AD}$ depending on the selected clinical and research classifications (Figure 1).

Preclinical AD, as the earliest stage in the $\mathrm{AD}$ continuum, comprises a long asymptomatic phase, in which individuals have evidence of AD pathology but no evidence of cognitive or functional decline, and their daily life is unaffected (8) (Figure 1). The duration of preclinical AD can vary between individuals, but typically lasts 6-10 years depending on the age of onset $(10,11)$. The risk of progression from preclinical AD to $\mathrm{MCI}$ due to $\mathrm{AD}$ (with/without $\mathrm{MBI}$ ) depends on a number of factors, including age, sex, and apolipoprotein E (ApoE) status (11, 12); however, not all individuals who have underlying $\mathrm{AD}$ pathology will go on to develop MCI or AD dementia $(13,14)$. A recent meta-analysis of six longitudinal cohorts followed up for an average of 3.8 years found that $20 \%$ of patients with preclinical AD progressed to $\mathrm{MCI}$ due to $\mathrm{AD}$ (11). A further study by Cho et al., with an average follow-up rate of 4 years, found that $29.1 \%$ of patients with preclinical AD progressed to $\mathrm{MCI}$ due to AD (12). 
Figure 1. Stages within the Alzheimer's disease continuum

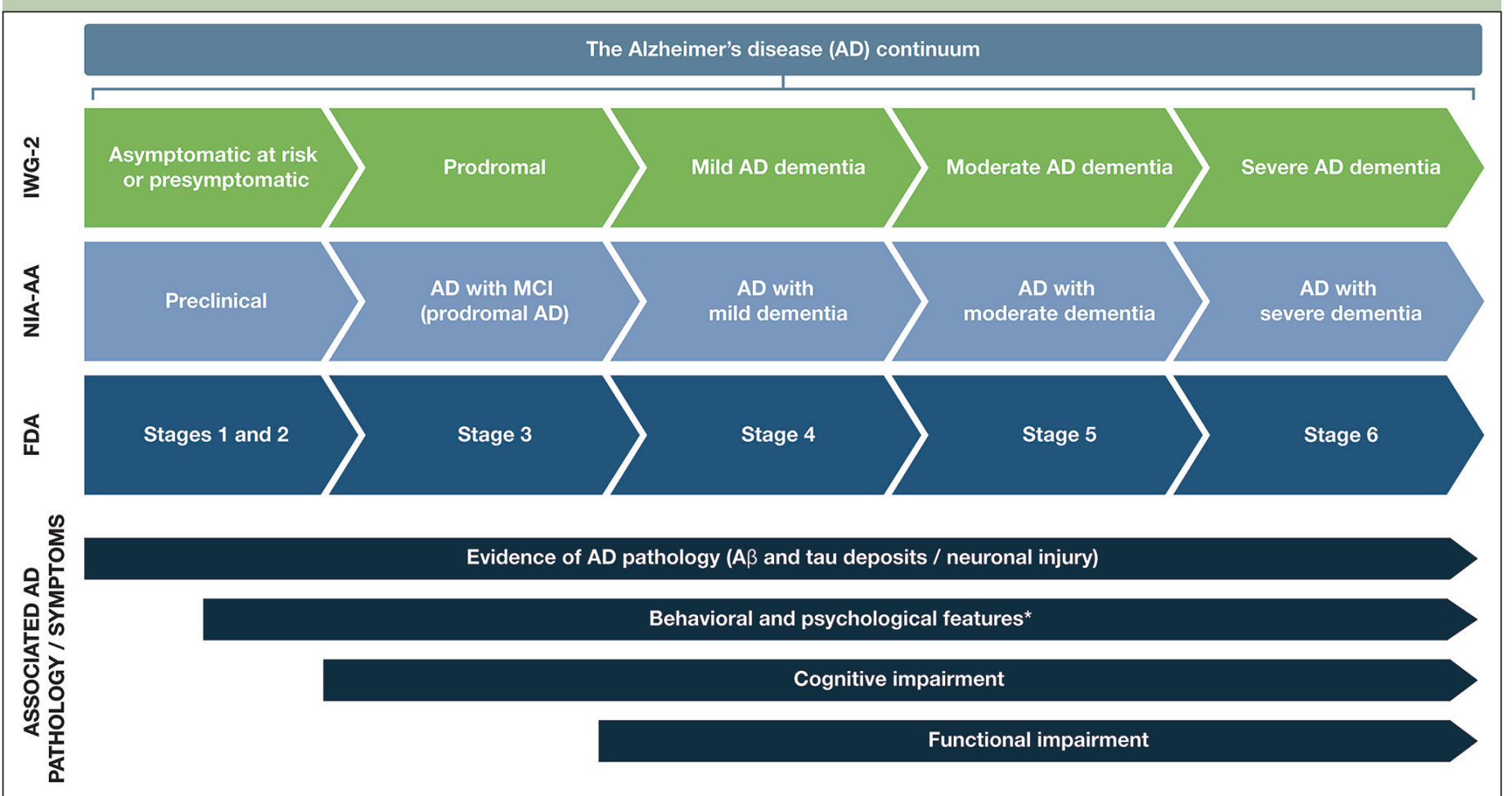

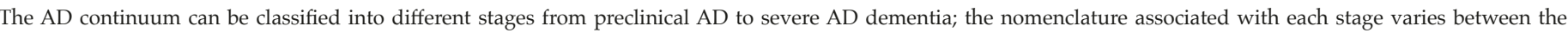

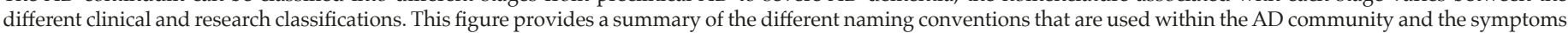

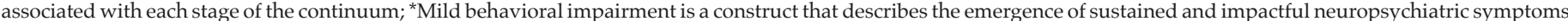

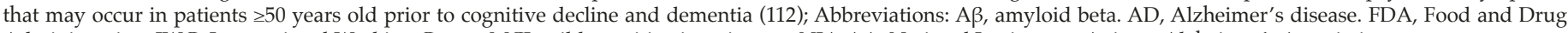
Administration. IWG, International Working Group. MCI, mild cognitive impairment. NIA-AA, National Institute on Aging-Alzheimer's Association

For patients who do progress to $\mathrm{MCI}$ due to $\mathrm{AD}$ (with/ without MBI), initial clinical symptoms typically include short-term memory impairment, followed by subsequent decline in additional cognitive domains (15) (Figure 1). On a day-to-day basis, an individual with MCI due to $\mathrm{AD}$ may struggle to find the right word (language), forget recent conversations (episodic memory), struggle with completing familiar tasks (executive function), or get lost in familiar surroundings (visuospatial function) (15, 16). As individuals have varying coping mechanisms and levels of cognitive reserve, patients' experiences and symptomology vary widely; however, patients tend to remain relatively independent at this stage, despite potential marginal deficits in function. The prognosis for patients with $\mathrm{MCI}$ due to $\mathrm{AD}$ can be uncertain; one study that followed up patients with $\mathrm{MCI}$ due to $\mathrm{AD}$ for an average of 4 years found that $43.4 \%$ progressed to $\mathrm{AD}$ dementia (12). Other studies reported $32.7 \%$ and $70.0 \%$ of individuals with $\mathrm{MCI}$ due to AD progress to AD dementia within 3.2 and 3.6 years of follow-up, respectively (17, 18). Patients who do progress to AD dementia will develop severe cognitive deficits that interfere with social functioning and will require assistance with activities of daily living (7) (Figure 1). As the disease progresses further, increasingly severe behavioral symptoms will develop that significantly burden patients and their caregivers, and the disease ultimately results in severe loss of independence and the need for round-the-clock care (3).

An early diagnosis of AD can provide patients the opportunity to collaborate in the development of advanced care plans with their family, caregivers, clinicians, and other members of the wider support team. Importantly, it also enables patients to seek early intervention with symptomatic treatment, lifestyle changes to maintain quality of life, and risk-reduction strategies that can provide clinically meaningful reductions in cognitive, functional, and behavioral decline (19-22). It can also help reduce healthcare system costs and constraints: a study by the Alzheimer's Association found that diagnosing $\mathrm{AD}$ in the early stages could save approximately $\$ 7$ trillion. These savings were due to lower medical and long-term care costs for patients with managed MCI than for those with unmanaged MCI and dementia (3). Furthermore, an early diagnosis will be vital for patients when a therapy addressing the underlying pathology of AD becomes available; currently 19 biologic compounds are under Phase 2 or 3 investigation (23). Physicians will need to be prepared for the approval of these treatments, to optimize the potential benefit and prolong preservation of patients' cognitive function and independence beyond that associated with current standard of care (19).

As the prevalence of $\mathrm{AD}$ continues to grow, the advancement of $\mathrm{AD}$ patient diagnosis will require an orchestrated effort, starting in the primary care setting 
Table 1. Patient case study

\section{A - Presentation}

- A 63-year-old Caucasian male patient (J.K) visited the memory clinic accompanied by his wife, having been referred by his PCP for evaluation of memory loss

- He presents with a history of an insidious onset of cognitive difficulties that have been progressive over the past 2 years. He considers his memory similar to his peers, and his deficits are not observable to people who know him casually

- At work, he has uncharacteristically confused orders and misplaced items, but has no difficulty keeping track of time, and his math, reading, and writing are intact. His wife says that people at work have started to notice him struggling to keep up and gently voiced their concerns to her

- The patient's basic activities of daily living are intact, but more complex instrumental activities of daily living are showing erosion. He still drives, but no longer wants to drive to areas he is not familiar with

- He presents with no gait difficulty or balance problems. In terms of neuropsychiatric symptoms, his mood is more labile. He chokes up easily and is overall a little more down but attributes this to the fear and frustration over what is happening to him. He does have some mixed neuropsychiatric symptoms with intermittent depressive symptoms and anxiety as well as irritability

B - Detect

- Past medical history significant for hypertension, dyslipidemia, mild obesity, and glucose intolerance

- No history of neurotoxic exposure, head injuries with post-concussion syndrome, strokes, or seizures

- A positive family history of dementia with his father and paternal grandmother, where onset occurred in the late $60 \mathrm{~s}$

C - Assess/Differentiate

Blood tests:

All normal, except for serum glucose of 115 and HgbA1c of $6.5 \%$

Neurologic examination:

Non-focal with faint bilateral palmomental reflex

Genotyping:

Homozygous for ApoE $\varepsilon 4$; no autosomal dominant genes

Cognitive assessments:

MoCA score of $21 / 30$

Structural imaging:

MRI showed mild small vessel disease and mild generalized atrophy

Hippocampal volume and ratio were reduced by $25 \%$ based on volumetric software

D - Diagnose

CSF biomarkers: $\quad$ Increased $p$-tau and $t$-tau

Reduced A $\beta 42$

$\mathrm{A} \beta 42 / 40$ ratio of 0.23

Diagnosis:

The most likely etiology is Alzheimer's disease, especially in view of a positive family history with similar age of onset, ApoE $\varepsilon 4$ status, and biomarker verification

E - Treat

- Advised patient to make lifestyle modifications, including controlling vascular risk factors and optimizing the management of other medical problems

- No treatment intervention required for neuropsychiatric symptoms at the time of diagnosis

- Provided information on local social worker to help support him and his family

- Encouraged regular follow-ups and monitoring

- Patient was referred for possible participation in a clinical trial

Abbreviations: A $\beta$, amyloid beta. ApoE, apolipoprotein E. HgbA1c, hemoglobin A1c. MoCA, Montreal Cognitive Assessment. MRI, magnetic resonance imaging. PCP, primary care physician. p-tau, phosphorylated tau. t-tau, total tau

and subsequently involving multiple healthcare provider $(\mathrm{HCP})$ specialties (e.g., nurse practitioner [NP] or physician assistant [PA]) throughout the disease continuum. Galvin et al. recently highlighted the need for HCPs to work as an integrated, patient-centered care team to accommodate the growing and diverse population of patients with $\mathrm{AD}$, beginning with diagnosis (24). For patients to receive a timely diagnosis, it is vital to implement an approach that minimizes the burden placed on the patient, clinician, and healthcare system (25). Here, we summarize the importance of establishing an early diagnosis of $\mathrm{AD}$, related practical 'how-to' guidance and considerations, and tools that can be used by healthcare providers throughout the diagnostic journey.

\section{The importance of an early diagnosis}

Historically, a diagnosis of AD has been one of exclusion, and one only made in the latter stages of disease (26); however, the disease process can take years 
to play out, exacting a significant toll on the patient, caregiver, and healthcare system along the way (27).

To mitigate this burden, the early and accurate detection of AD-associated symptoms in clinical practice represents a critically needed but challenging advancement in AD care $(19,28-30)$. Usually, a patient with early signs/symptoms of $\mathrm{AD}$ will initially present in a primary care setting (30). For some patients, minor changes in cognition and/or behavior may be detected during a routine wellness visit or an appointment to discuss other comorbidities (24). As the PCP is often the first to observe a patient's initial symptomatology, it is vital they recognize the early signs and symptoms, and understand how to use the most appropriate assessment tools designed to detect these early clinical effects of the disease.

Because the neuropathologic hallmarks of $\mathrm{AD}(\mathrm{A} \beta$ plaques and NFTs) can be detected decades prior to the onset of symptoms $(6,7)$, biomarkers reflecting this underlying pathology represent an important opportunity for early identification of patients at greatest risk of developing MCI due to AD. Biomarkers support the diagnosis of $\mathrm{AD}$ (especially important early on when symptoms can be subtle), and the U.S. Food and Drug Administration (FDA) has recently published guidelines that endorse their use in this population (9). The National Institute on Aging-Alzheimer's Association (NIAAA) has recently created a research framework that acknowledges the use of biomarkers for diagnosing AD in vivo and monitoring disease progression (7).

Important biomarker information can be gathered from imaging modalities such as magnetic resonance imaging (MRI) and positive emission tomography (PET) that visualize early structural and molecular changes in the brain, respectively $(25,30)$. Fluid biomarker testing, such as cerebrospinal fluid (CSF) can also be used; CSF biomarkers can directly reflect the presence of $A \beta$ and aggregated tau within the brain $(7,31)$. As will be discussed in more depth later in this article, a large number of clinical studies have shown that $A \beta$ and tau biomarkers can contribute diagnostically important information in the early stages of disease (32). There is ongoing research to expand the current range of tests that can be used by clinicians as part of the multistage diagnostic process (25). For instance, once approved, blood-based biomarkers could be used to identify patients at risk of developing $\mathrm{AD}$ and for monitoring disease progression $(33,34)$, which would also reduce the current capacity constraints associated with PET imaging (25).

\section{Practical guide for an early diagnosis of Alzheimer's disease in clinical practice}

As already raised, recent recommendations for evolving $\mathrm{AD}$ care to a more patient-centric, transdisciplinary model include guidance on realizing an efficient diagnostic process-one in which HCPs, payers, and specialists are encouraged to combine their efforts to ensure the early warning signs of $\mathrm{AD}$ are not overlooked (24). The recommendations include dividing the diagnosis of $\mathrm{AD}$ into the following steps: detect, assess / differentiate, diagnose, and treat (Figure 2). We present here a practical guide for the early diagnosis of $\mathrm{AD}$, based on this outlined approach, including a case study to highlight each of these key steps.

\section{Step 1: Detect}

\section{The role of primary care in the early detection of $A D$}

The insidious and variable emergence of symptoms associated with $\mathrm{AD}$ and other dementias can make recognition extremely challenging, particularly in a primary care setting $(30,35)$. Clinicians often have limited time with patients, so it is vital that they are able to quickly and accurately recognize the early signs and symptoms associated with $\mathrm{AD}$ (Table 2) $(3,30,36)$, and training for nurses, NPs, and PAs who may have more time to observe patients should provide substantial benefits. Although extremely variable, initial symptoms may include short-term memory loss or psychological concerns, including depressive symptoms and a loss of purpose (36).

Patients, family members, and even HCPs themselves may present barriers to the diagnosis of early-stage AD. Patients may hide their symptoms or even avoid making an appointment until their symptoms significantly affect their day-to-day life due to fear of the stigma associated with a diagnosis of AD (19). Additionally, patients, family members, and PCPs/HCPs may dismiss or misinterpret symptoms as simply part of the normal aging process (30). Retrieving information from a trusted family member or informant/caregiver is essential when trying to assess a patient for suspected $\mathrm{AD}$, as this perspective can provide a more objective understanding of the daily routine, mood, and behavior of the patient, and how this may have changed over time (30). For patients presenting with even subtle symptoms associated with $\mathrm{AD}$, it is important that the $\mathrm{PCP} / \mathrm{HCP}$ conducts an initial assessment to confirm the presence of symptoms using a validated assessment for early-stage AD detection (Figure 2; Step 2: Assess/Differentiate).

\section{Case study: Presentation}

A 63-year-old Caucasian male (J.K.) presented to his PCP with short-term memory loss over the last 2 years (Table 1A). Accompanied by his wife, he acknowledged his job had been affected by issues with his short-term memory; however, he considered his memory similar to that of his peers. His wife reported that people at work had started to notice him struggling to keep up, and also that family had to remind him of his upcoming appointments. He admitted to having intermittent 
Table 2. Symptoms associated with suspected early stage Alzheimer's disease

\begin{tabular}{|c|c|c|c|c|c|}
\hline 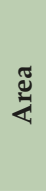 & Cognition $(3,30)$ & $\begin{array}{l}(19)(1,1) \\
\text { Behavior }(3,30,36)\end{array}$ & Psychological $(3,36)$ & Physical $(3,36)$ & Other (36) \\
\hline 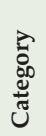 & $\begin{array}{l}\text { - Short-term memory loss } \\
\text { - Word-finding difficulties } \\
\text { (anomia) or communication } \\
\text { difficulties }\end{array}$ & $\begin{array}{l}\text { - Withdrawal from social } \\
\text { activities } \\
\text { - Disinhibition and impulsivity }\end{array}$ & $\begin{array}{l}\text { - Depression } \\
\text { - Mood disturbances } \\
\text { - Apathy }\end{array}$ & $\begin{array}{l}\text { - Visuospatial problems } \\
\text { - Gait impairment }\end{array}$ & - Sleep disorder \\
\hline 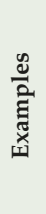 & $\begin{array}{l}\text { - Forgetting appointments, } \\
\text { names, and recent events } \\
\text { - Frequently misplacing items } \\
\text { - Trouble finding exact words } \\
\text { to express oneself, or loss of } \\
\text { word meaning }\end{array}$ & $\begin{array}{l}\text { - Inability to participate in } \\
\text { meaningful social situations } \\
\text { - Inappropriate social conduct } \\
\text { such as eating from someone } \\
\text { else's plate, or inappropriate } \\
\text { language } \\
\text { - Poor or decreased judgment }\end{array}$ & $\begin{array}{l}\text { - Changes in mood or } \\
\text { personality } \\
\text { - Feeling of helplessness and a } \\
\text { loss of purpose in life } \\
\text { - Loss of initiation }\end{array}$ & - Frequent falls & $\begin{array}{l}\text { - Rapid eye movement } \\
\text { disorder, such as acting } \\
\text { out dreams }\end{array}$ \\
\hline
\end{tabular}

Figure 2. A stepwise infographic to highlight key stages within the diagnostic process, along with the recommended tests to support each step

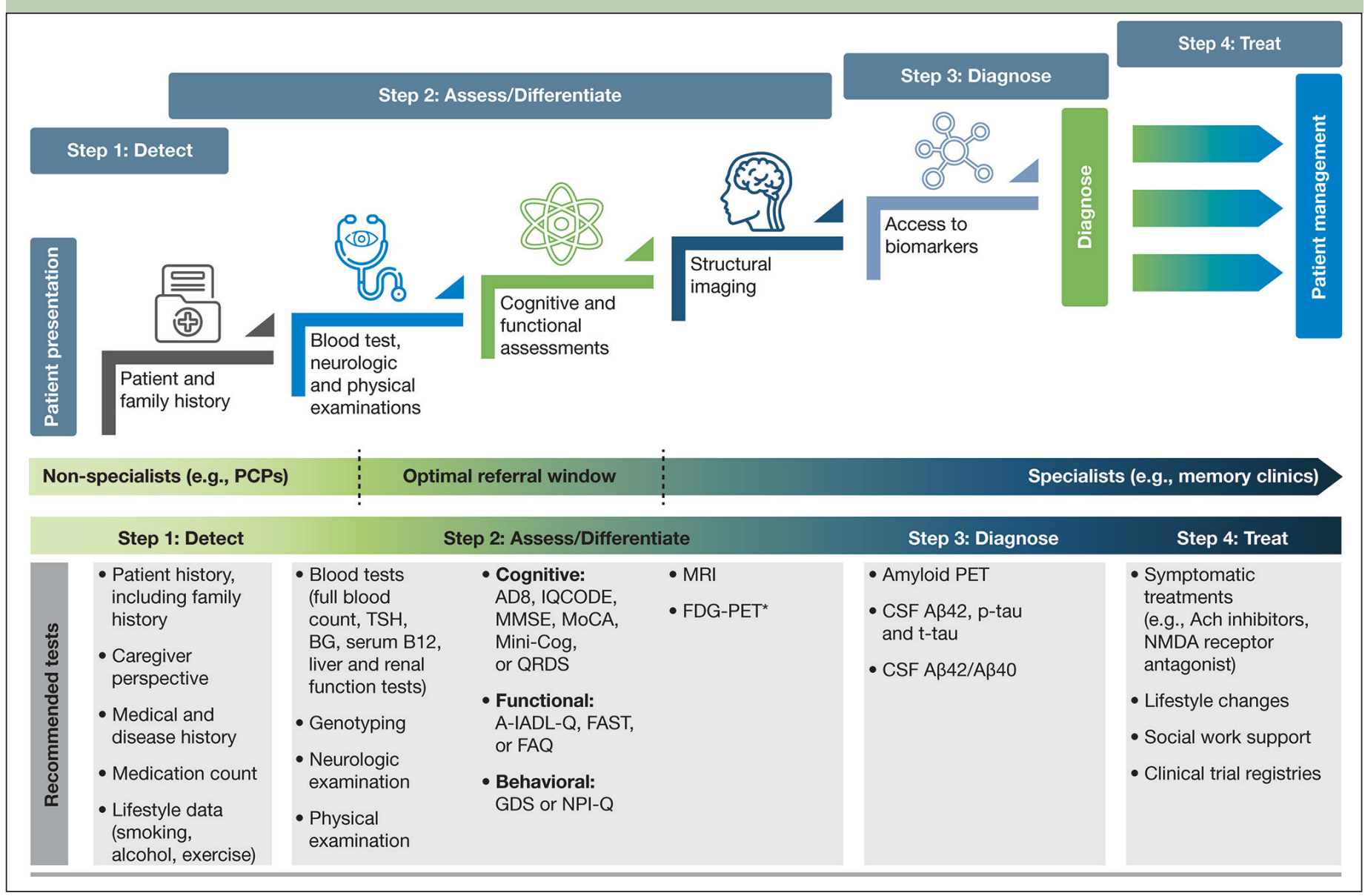

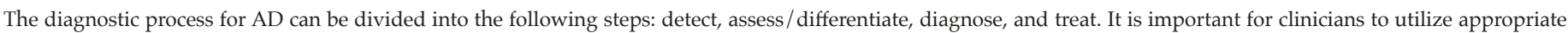

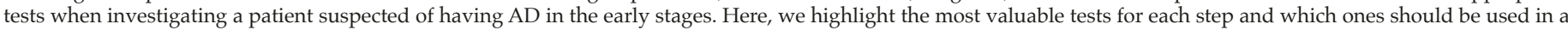

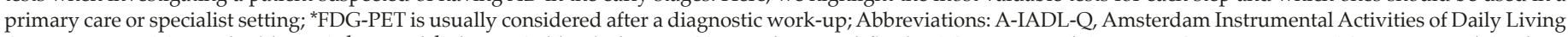

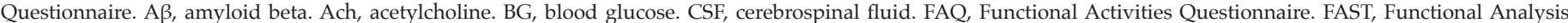

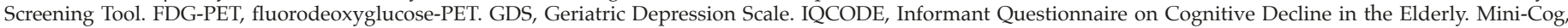

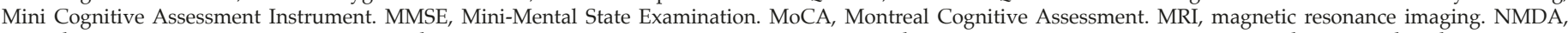

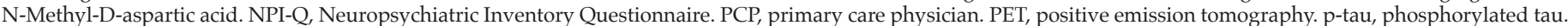
QDRS, Quick Dementia Rating System. TSH, thyroid-stimulating hormone. t-tau, total tau 
Table 3. Example questions for a clinician conducting an initial assessment with a patient and caregiver (30)

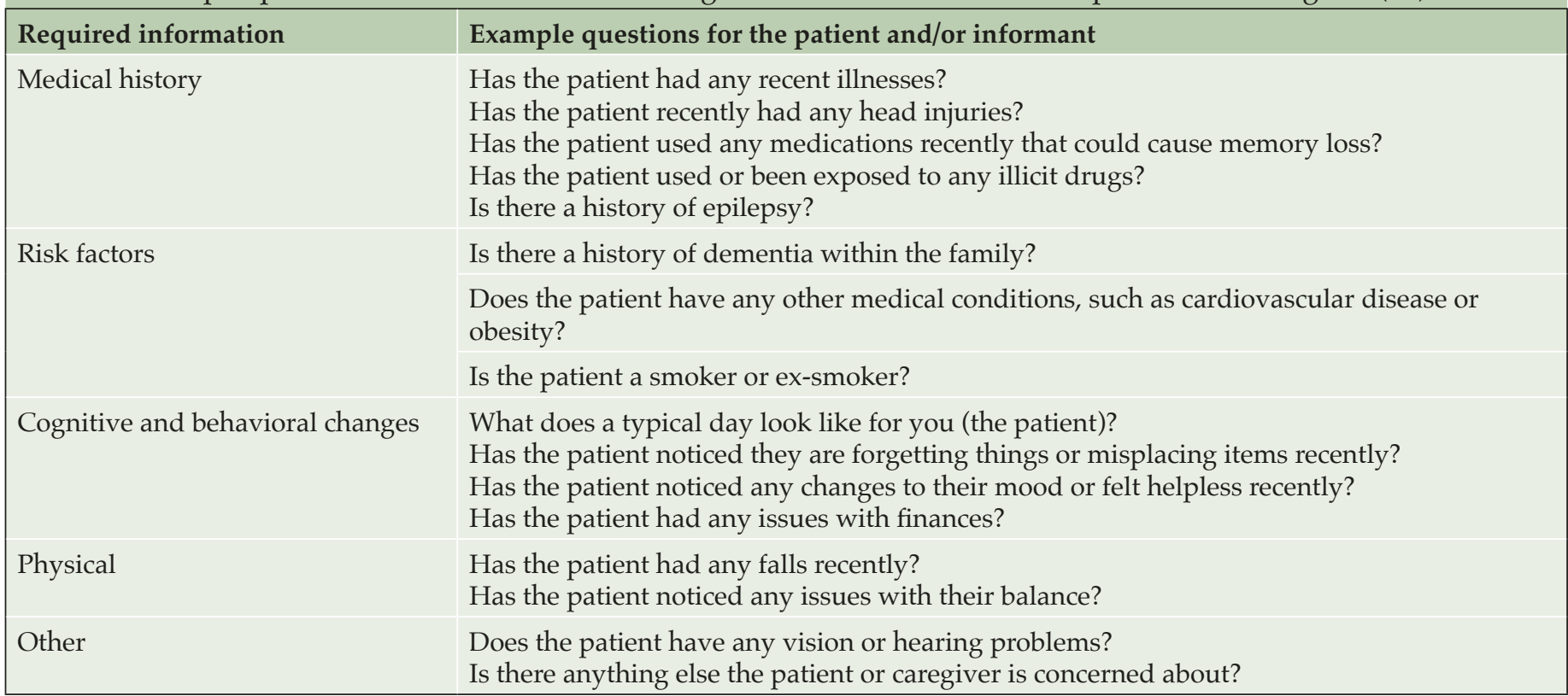

depressive symptoms and anxiety, as well as irritability. Based on the patient's symptoms, the PCP felt his presentation warranted further clinical assessment.

\section{Step 2: Assess and differentiate}

\section{Primary care: Initial assessment when a patient presents}

When a patient initially presents with symptoms consistent with early stages of $\mathrm{AD}$, a clinician must first conduct a comprehensive clinical assessment to rule out other potential non-AD causes of cognitive impairment (Figure 2). PCPs are well placed to conduct these initial assessments, as they may not require specialist input or hospital tests. During the initial assessment, the primary objective of the clinician should be to exclude possible reversible causes of cognitive impairment, such as depression, or vitamin, hormone, and electrolyte deficiencies (37). The initial assessment should include a thorough history to identify potential risk factors associated with AD, including a family history of $\mathrm{AD}$ or related dementias in first-degree relatives (31, 38). Other known risk factors for AD that should be identified include age, female sex, ApoE $\varepsilon 4$ status, physical inactivity, low education, diabetes, and obesity (3). It is also important to review for pre-existing medical conditions or prescribed medications that could be a cause of the patient's cognitive impairment (36). Additionally, when conducting a thorough history, openended, probing questions should be directed to both the patient and the informant to ascertain how the patient's cognition has changed over time and how the cognitive deficits affect their everyday activities; example questions for the initial assessment are detailed in Table 3 (30). Engaging with informants/caregivers is key to capturing additional information to help support all assessments. A routine differential diagnosis of $A D$ begins with a detailed history, physical and neurologic examinations, and bloodwork analyses, followed by cognitive assessments and functional evaluation (Figure 2).

\section{Primary care: Physical examination and blood analyses}

A physical examination and blood tests can identify comorbid contributory medical conditions and reversible causes of cognitive impairment. A physical examination, including a mental status and neurological assessment, should be conducted to detect conditions such as depression and, for example, to look for signs such as issues with speaking or hearing as well as signs that could indicate a stroke (37). As part of the physical exam, a physician may ask the patient about diet and nutrition, review all medications (to see if these are the cause of any cognitive impairment, e.g. anti-cholinergics, analgesics, or sleep aids and anxiolytics), check blood pressure, temperature and pulse, and listen to the heart and lungs $(36,39)$.

Blood tests can rule out potentially treatable illnesses as a cause of cognitive impairment, such as vitamin $\mathrm{B}_{12}$ deficiency or thyroid disease (37). Suggested blood analyses include: 1) complete blood cell count; 2) blood glucose; 3) thyroid-stimulating hormone; 4) serum $B_{12}$ and folate; 5) serum electrolytes; 6) liver function; and 7) renal function tests (30). Although not routinely used in clinical practice, clinicians may request ApoE genotyping, as this can help assess the genetic risk of developing AD. ApoE is the dominant cholesterol carrier within the brain 
Table 4. Cognitive, functional, and behavioral assessments to support the diagnosis of Alzheimer's disease in a primary care and specialist setting

\begin{tabular}{|c|c|c|c|c|c|c|c|c|c|}
\hline \multicolumn{10}{|c|}{ Primary Care } \\
\hline $\begin{array}{l}\text { Type of } \\
\text { assessment }\end{array}$ & Assessment & $\begin{array}{l}\text { Number } \\
\text { of items (if } \\
\text { appropriate) }\end{array}$ & $\begin{array}{l}\text { Time taken } \\
\text { to complete } \\
\text { assessment } \\
\text { (minutes) }\end{array}$ & Scoring system & $\begin{array}{l}\text { Sensitivity and } \\
\text { specificity }\end{array}$ & $\begin{array}{l}\text { Available } \\
\text { in different } \\
\text { languages }\end{array}$ & $\begin{array}{l}\text { Shortened } \\
\text { version } \\
\text { available }\end{array}$ & $\begin{array}{l}\text { Scores can be } \\
\text { demographically } \\
\text { adjusted, e.g. } \\
\text { education level }\end{array}$ & $\begin{array}{l}\text { Justification } \\
\text { for use }\end{array}$ \\
\hline \multirow[t]{5}{*}{ Cognitive } & $\begin{array}{l}\text { MMSE } \\
(28,102,103)\end{array}$ & 30 & $5-10$ & $23-24$ & $\begin{array}{l}\text { Sensitivity: } \\
85-100 \% \\
\text { Specificity: } \\
66-100 \%\end{array}$ & Yes & Yes & Yes & $\begin{array}{l}\text { Minimal } \\
\text { training } \\
\text { requirements }\end{array}$ \\
\hline & $\begin{array}{l}\text { MoCA } \\
(28,46,102,104)\end{array}$ & 12 & 10 & $\begin{array}{l}<26 \text { for MCI or } \\
\text { dementia }\end{array}$ & $\begin{array}{l}\text { Sensitivity: } \\
78-100 \% \\
\text { Specificity: } \\
65-94 \%\end{array}$ & Yes & Yes & Yes & $\begin{array}{l}\text { Minimal } \\
\text { training } \\
\text { requirements }\end{array}$ \\
\hline & $\begin{array}{l}\text { Mini-Cog } \\
(28,102,105)\end{array}$ & $\begin{array}{l}3 \text { item recall } \\
\text { with clock } \\
\text { drawing }\end{array}$ & $2-3$ & $\begin{array}{l}\text { Recall } 2 / 3 \\
\text { items Clock } \\
\text { drawing used } \\
\text { to determine } \\
\text { presence of } \\
\text { cognitive } \\
\text { deficits }\end{array}$ & $\begin{array}{l}\text { Sensitivity } \\
\text { and specificity } \\
\text { comparable to } \\
\text { MMSE }\end{array}$ & Yes & No & No & $\begin{array}{l}\text { Brief assessment } \\
\text { and easy } \\
\text { to interpret } \\
\text { No training } \\
\text { requirements }\end{array}$ \\
\hline & AD8 $(28,106)$ & 8 & $2-3$ & $\begin{array}{l}\text { Scores greater } \\
\text { than } 2 \text { signify } \\
\text { impairment }\end{array}$ & $\begin{array}{l}\text { Sensitivity: } 90 \% \\
\text { Specificity: } 68 \%\end{array}$ & Yes & No & No & $\begin{array}{l}\text { Brief assessment } \\
\text { for cognitive } \\
\text { impairment }\end{array}$ \\
\hline & $\begin{array}{l}\text { IQCODE } \\
(28,107)\end{array}$ & 16 or 26 & 10 & $\begin{array}{l}\text { Scores greater } \\
\text { than } 3.44 \text { signify } \\
\text { impairment }\end{array}$ & $\begin{array}{l}\text { Sensitivity: } \\
76-100 \% \\
\text { Specificity: } \\
65-86 \%\end{array}$ & Yes & Yes & No & $\begin{array}{l}\text { Measures } \\
\text { decline from } \\
\text { premorbid level }\end{array}$ \\
\hline Functional & FAQ $(46-48,108)$ & 10 categories & $5^{*}$ & $\begin{array}{l}0-3 \text { scale } \\
(0=\text { normal; } \\
3=\text { dependent })\end{array}$ & $\begin{array}{l}\text { Sensitivity: } 90 \% \\
\text { Specificity: } 83 \%\end{array}$ & Yes & No & No & $\begin{array}{l}\text { Highly reliable } \\
\text { assessment }\end{array}$ \\
\hline \multirow[t]{2}{*}{ Behavioral } & GDS $(28,49,109)$ & 15 or 30 & $5-10$ & $\begin{array}{l}\geq 5 \text { suggestive of } \\
\text { depression; } \geq 10 \\
\text { significant of } \\
\text { depression* }\end{array}$ & $\begin{array}{l}\text { No data } \\
\text { available }\end{array}$ & Yes & Yes & No & $\begin{array}{l}\text { Reliable } \\
\text { assessment for } \\
\text { early stages of } \\
\text { dementia }\end{array}$ \\
\hline & $\begin{array}{l}\text { NPI-Q } \\
(49-51,110)\end{array}$ & 12 & 5 & $\begin{array}{l}0-3 \text { scale } \\
\text { ( } 0=\text { none; } \\
3=\text { severe })\end{array}$ & $\begin{array}{l}\text { Sensitivity: } 86 \% \\
\text { Specificity: } 76 \%\end{array}$ & Yes & No & No & $\begin{array}{l}\text { Brief and } \\
\text { reliable } \\
\text { assessment }\end{array}$ \\
\hline \multicolumn{10}{|l|}{ Specialist } \\
\hline $\begin{array}{l}\text { Type of } \\
\text { assessment }\end{array}$ & Assessment & $\begin{array}{l}\text { Number } \\
\text { of items (if } \\
\text { appropriate) }\end{array}$ & $\begin{array}{l}\text { Time taken } \\
\text { to complete } \\
\text { assessment } \\
\text { (minutes) }\end{array}$ & Scoring system & $\begin{array}{l}\text { Sensitivity and } \\
\text { specificity }\end{array}$ & $\begin{array}{l}\text { Available } \\
\text { in different } \\
\text { languages }\end{array}$ & $\begin{array}{l}\text { Shortened } \\
\text { version } \\
\text { available }\end{array}$ & $\begin{array}{l}\text { Scores can be } \\
\text { demographically } \\
\text { adjusted, e.g. } \\
\text { education level }\end{array}$ & $\begin{array}{l}\text { Justification } \\
\text { for use }\end{array}$ \\
\hline Cognitive & QDRS $(28,52)$ & 10 & $3-5$ & $\begin{array}{l}\text { Scores of } 2 \text { or } \\
\text { greater signify } \\
\text { impairment }\end{array}$ & $\begin{array}{l}\text { Sensitivity: } 84 \% \\
\text { Specificity: } 75 \%\end{array}$ & Yes & No & No & $\begin{array}{l}\text { Highly reliable } \\
\text { assessment. } \\
\text { No training } \\
\text { requirements }\end{array}$ \\
\hline \multirow[t]{2}{*}{ Functional } & $\begin{array}{l}\text { A-IADL-Q } \\
(53,54,111)\end{array}$ & $\leq 70$ items & 10 & $\begin{array}{l}\text { 5-point rating } \\
\text { system }\end{array}$ & $\begin{array}{l}\text { Sensitivity: } 74 \% \\
\text { Specificity: } 65 \%\end{array}$ & Yes & Yes & No & $\begin{array}{l}\text { Sensitive to } \\
\text { early stages } \\
\text { of } A D\end{array}$ \\
\hline & FAST (55) & 28 & $10-15$ & $\begin{array}{l}\text { Yes/No for } \\
\text { presence of } \\
\text { behavioral } \\
\text { concern }\end{array}$ & $\begin{array}{l}\text { No data } \\
\text { available }\end{array}$ & No & No & No & $\begin{array}{l}\text { Useful test } \\
\text { to assess } \\
\text { behavioral } \\
\text { concerns } \\
\text { from multiple } \\
\text { informants }\end{array}$ \\
\hline
\end{tabular}

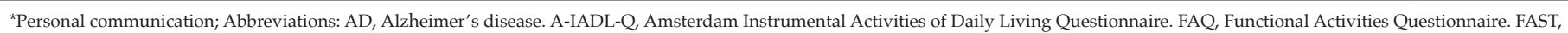

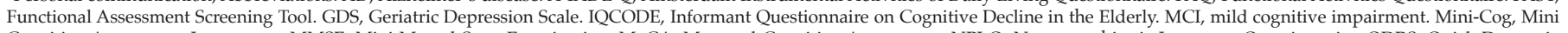

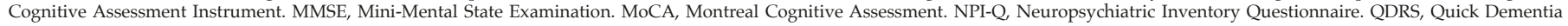
Rating System

that supports lipid transport and injury repair $(40,41)$, and the APOE gene exists as three polymorphic alleles: $\mathrm{APOE} \varepsilon 2, \varepsilon 3$, and $\varepsilon 4$. The $\varepsilon 4$ allele of ApoE is associated with increased $\mathrm{AD}$ risk, whereas the $\varepsilon 2$ allele is protective $(40,42)$. The number of ApoE $\varepsilon 4$ alleles a person carries increases their risk of developing $\mathrm{AD}$ and the age of disease onset (43). Homozygous $\varepsilon 4$ carriers (those with two copies of the $\varepsilon 4$ allele) have the greatest risk of developing $\mathrm{AD}$ and the lowest average age of onset (43). In some practice settings, ApoE genotyping can only be conducted by a genetic counselor; a referral for more comprehensive genetic testing may be considered by the HCP if there is a family history of early-onset $\mathrm{AD}$ or dementia. Consumer tests are also becoming more readily available for patients wanting to determine their risk of developing diseases such as AD based on genetic risk factors (44). 
Table 5. Comparison of key CSF and amyloid PET considerations for amyloid confirmation

\begin{tabular}{|l|l|l|}
\hline Factor & Amyloid PET & CSF \\
\hline $\begin{array}{l}\text { Cost } \\
\text { Radiation }\end{array}$ & Yigh cost (70) & Moderate cost (82) \\
\hline $\begin{array}{l}\text { Headache } \\
\text { Technique }\end{array}$ & Very rare (80) & No \\
& $\begin{array}{l}\text { Visual interpretation depends on the observer's experience (84) } \\
\text { Lacks a clear cutoff value between normal and pathologic }\end{array}$ & $\begin{array}{l}\text { Patient assessed for coagulopathy; anticoagulant therapy } \\
\text { findings (84) }\end{array}$ \\
\hline & $\begin{array}{l}\text { Contraindicated (85) } \\
\text { Complicated lumbosacral spinal anatomy (85) }\end{array}$ \\
\hline
\end{tabular}

Abbreviations: CSF, cerebrospinal fluid. PET, positron emission tomography

\section{Primary care: Cognitive, functional, and behavioral assessments}

\section{Cognitive assessments}

If a patient is suspected of having $\mathrm{AD}$ following an initial assessment in primary care, and they are $<65$ years old, or if the case is complex, a referral to a dementia specialist such as a neurologist, geriatrician, or geriatric psychiatrist may be required for further evaluation. The specialist would then use an appropriate battery of cognitive, functional, and behavioral tests to assess the different aspects of disease, and ultimately to confirm diagnosis. However, not all patients with suspected cognitive deficits are immediately referred to a dementia specialist at this stage, which is only partly due to limited numbers of specialists (25) (Figure 2). In clinical practice, a two-stage process is often employed. This involves an initial 'triage' step conducted by non-specialists to clinically assess and select those patients who require further evaluation by a dementia specialist (45). During this 'triage' step, there are several clinical assessments available to non-specialists for assessing the presence of cognitive and functional impairments and behavioral symptoms (Table 4$)(28,35,46-55)$.

Previous research has shown that clinicians have a tendency to choose one assessment over another due to their familiarity with the assessment, time constraints, or specific resources available to them within their clinic (30), but clinicians need to be aware of, and prepared to use, the most patient-appropriate assessments: the cultural, educational, and linguistic needs of the patient are important considerations $(30,36,56-58)$. Some assessments have been translated into different languages or shortened, or have education-adjusted scoring classifications, where required (56-58).

Cognitive assessments that can be conducted quickly ( $<10$ minutes), such as the Mini-Mental State Examination (MMSE) or Montreal Cognitive Assessment (MoCA), can be used by non-specialists to identify the presence and severity of cognitive impairment in patients before referring to a dementia specialist (Table 4) (36). Both the
MMSE and MoCA are used globally in clinical practice, particularly in primary care, but vary in terms of their sensitivity to identify AD in the early stages $(28,59)$. The MMSE is sensitive and reliable for identifying memory and language deficits in general but has limitations in identifying impairments in executive functioning (59). MoCA was originally developed to improve the detection of MCI (28) and is more sensitive than the MMSE in its assessment of memory, visuospatial, executive, and language function, and orientation to time and place (59). Both tests are relatively easy to administer and take around 10 minutes to complete. Neither assessment requires extensive training by the clinician, although MoCA users do need to undergo a 1-hour certification as mandated by the MoCA Clinic and Institute $(28,60)$.

For time-constrained clinicians, the Mini Cognitive Assessment Instrument (Mini-Cog) may be an appropriate tool to assess cognitive deficits that focus on memory, and components of visuospatial and executive function (Table 4). The assessment includes the individual learning three items from a list, drawing a clock, and then recalling the three-item list. The Mini-Cog can be useful for clinicians in primary care, as it requires no training and the results are easy to interpret. As an alternative to these tests, PCPs might also consider using an informant-based structured questionnaire such as the AD8 or Informant Questionnaire on Cognitive Decline in the Elderly to help guide discussions with the patient and caregiver (Table 4) (28).

\section{Functional assessments}

Functional assessments are valuable in identifying changes in a patient's day-to-day functioning through the evaluation of their instrumental activities of daily living (IADLs). IADLs are complex activities that are necessary for the individual to function independently (e.g., cooking, shopping, and managing finances) and can be impaired during the early stages of cognitive impairment. While it is possible that functional decline may occur as a part of normal aging, a decline in a person's IADL performance is strongly associated with neurodegenerative diseases such as $\mathrm{AD}$ (61). In the early 
stages of $\mathrm{AD}$, patients may be functionally independent, and any impairment in IADLs may be subtle, such as difficulties paying bills or driving to new places. A patient's functional independence is essential for their well-being and mental health (62), particularly in the early stages of the disease when the individual may still be working and socializing relatively independently (3). Consequently, functional independence is one of the most important clinical features for patients with AD. As the disease progresses, and patients have increasing functional impairment, this significantly impacts on their independence, and subsequently their and their family/ caregiver's quality of life.

Functional assessment is, therefore, an integral part of the diagnostic process for AD. The Functional Activities Questionnaire (FAQ) is an informant questionnaire that assesses the patient's performance over a 4-week period and may take only a few minutes to complete (Table 4). The questionnaire is scored from 'normal' to 'dependent', using numerical values assigned to categories, with higher scores indicative of increasing impairment (47). Previous research has shown that the FAQ has high sensitivity and reliability for detecting mild functional impairment in patients with MCI (47).

Determining an individual's functional independence can be challenging and the clinician may require additional input from an informant to determine a patient's functional decline and their ongoing ability to conduct activities of daily living (37). The clinician can gain greater insight through the informant into the patient's day-to-day life and any issues the patient is having at home. This type of information is vital to the clinician, and when combined with other assessment tools, can help to narrow the differential diagnosis.

\section{Behavioral assessments}

Patients with suspected AD may experience several behavioral symptoms such as anxiety, disinhibition, apathy, and depression (Table 2). In the early stages of disease, such symptoms are generally associated with poor long-term outcomes and caregiver burden, and are particularly distressing to both patients and their families (63). It is important for clinicians to use appropriate assessments to identify behavioral and psychiatric symptoms that are caused by neurodegenerative diseases, such as AD, rather than by alternative causes, such as a mood disorder.

The Geriatric Depression Scale (GDS) and Neuropsychiatric Inventory Questionnaire (NPI-Q) can be used by clinicians to assess neuropsychiatric symptoms in patients for whom early-stage $A D$ is suspected (Table 4). The GDS is a 15 -item (or longer 30-item) questionnaire that assesses mood, has good reliability in older populations for detecting depression, and can be completed by the patient within 5-10 minutes (63). The NPI-Q can be used in conjunction with or as an alternative to the GDS. The NPI-Q is completed by a knowledgeable informant or caregiver who can report on the patient's neuropsychiatric symptoms. The NPI-Q can be conducted in around 5 minutes to determine both the presence and severity of symptoms across several neuropsychiatric domains including depression, apathy, irritability, and disinhibition (49). Consequently, as it assesses depression, it can be used as an alternative to GDS if time constraints do not allow for both to be completed.

Behavioral symptoms can be non-specific, so it is important for clinicians to consider and rule out other potentially treatable causes of impairment when assessing this domain. For example, depression is associated with concentration and memory issues (64); apathy can occur in non-depressed elderly individuals and can impact cognitive function (65). Signs/symptoms such as social withdrawal, feelings of helplessness, or loss of purpose should be investigated closely, as these could be indicative of depression alone. It is important for clinicians to recognize that if changes over time in cognitive symptoms and mood symptoms match, then depression is most likely to be the root cause of subtle cognitive decline, rather than AD (28).

\section{Primary care clinician checklist}

If $\mathrm{AD}$ is still suspected following clinical assessment, referral to a specialist for further diagnostic testing, including imaging and fluid biomarkers, may be required. It is important the clinician confirms the following checks/assessments before the patient undergoes further evaluation:

\section{Primary care clinician checklist}

- Confirm medical and family history

- Review the patient's medications for any that could cause cognitive impairment

- Perform blood tests to eliminate potential reversible causes of cognitive impairment

- Conduct a quick clinical assessment to confirm the presence of cognitive impairment

\section{Specialist role in assessment}

Following the initial assessment in primary care, further cognitive, behavioral, functional, and imaging assessments can be carried out in a specialist setting. With their additional AD experience, access to other specialties, and possibly fewer time constraints than the $\mathrm{PCP}$, the specialist is able to conduct a more comprehensive testing battery, using additional clinical assessments and biomarkers to determine causes of impairment and confirm diagnosis (Figure 2). 


\section{Cognitive assessments}

Because the cognitive impacts of early-stage AD may vary from patient to patient, it is important to consider which cognitive domains are affected in these early stages when considering which assessments to use. Specialists are able to conduct a full neuropsychological test battery that covers the major cognitive domains (executive function, social cognition/emotions, language, attention/ concentration, visuospatial and motor function, learning and memory); preferably, a battery should contain more than one test per domain to ensure adequate sensitivity in capturing cognitive impairment (66). This step can help with obtaining an in-depth understanding of the subtle changes in cognition seen in the early stages of $\mathrm{AD}$ and enables the clinician to monitor subsequent changes over time.

Typically, episodic memory, executive function, visuospatial function, and language are the most affected cognitive domains in the early stages of $\operatorname{AD}(29,67,68)$. Currently, most cognitive assessment tools focus on a subset of the overall dimensions of cognition; it is therefore vital the clinician chooses the correct test to assess impairment in these specific cognitive domains that could be indicative of AD in the early stages. As cognitive impairment in the early stages of $\mathrm{AD}$ can be subtle and vary significantly between individuals (29), clinicians must choose appropriate, sensitive tests that can detect these changes and account for a patient's level of activity and cognitive reserve (29). If there is large disparity in results across cognitive assessments, it is important for the clinician to shape their assessments based on the patient's history. If the patient's history is positive for neurodegenerative disease, but one assessment does not reflect this, it is important to conduct further tests to ascertain the cause of the cognitive impairment.

The Quick Dementia Rating System (QDRS) can be used by specialists to assess cognitive impairment (Table $4)$. This short questionnaire ( $<5$ minutes) is completed by a caregiver/informant and requires no training. The QDRS assesses several cognitive domains known to be affected by $\mathrm{AD}$, including memory, language and communication abilities, and attention. The questionnaire can reliably discriminate between individuals with and without cognitive impairment and provides accurate staging for disease severity (28).

\section{Functional assessments}

The Amsterdam IADL Questionnaire (A-IADL-Q) and Functional Assessment Screening Tool (FAST) can both be used to assess a patient's functional ability (Table 4) (53). The A-IADL-Q is a reliable computerized questionnaire that monitors a patient's cognition, memory, and executive functioning over time. This questionnaire is completed by an informant of the patient and takes 10 minutes to complete (53). For patients with suspected early stage $A D$, the A-IADL-Q is a useful tool to monitor subtle changes in IADL independence over time and is less influenced by education, gender, and age than other functional assessments (53). The FAST is a useful assessment for clinicians to identify the occurrence of functional and behavioral problems in patients with suspected $\mathrm{AD}$. The questionnaire is completed by informants who interact with the patient regularly; informants are required to answer Yes/No to a number of questions focusing on social and non-social scenarios (55).

\section{Structural imaging}

Structural imaging, such as MRI, provides clinically useful information when investigating causes of cognitive impairment (69) (Figure 2). MRI is routinely conducted to exclude alternative causes of cognitive impairment, rather than support a diagnosis of $\operatorname{AD}(37,70)$. It is well known that medial temporal lobe atrophy is the best MRI marker for identifying patients in the earliest stages of AD $(70,71)$; however, specific patterns of atrophy may also be indicative of other neurodegenerative diseases. Atrophy alone is rarely sufficient to make a diagnosis. MRI findings can help to narrow the differential diagnosis, and the results should be considered in the context of the patient's age and clinical examination (69-71).

Clinicians are advised to take a stepwise approach when reviewing structural imaging reports of a patient with suspected AD. These steps include: 1) excluding brain pathology that may be amenable to surgical intervention (e.g., the scan will show regions of hyper- or hypointensity rather than a uniform signal); 2) assessing for brain microbleeds (e.g., looking at signal changes within different areas of the brain can identify vascular comorbidities); and 3) assessing atrophy (e.g., medial temporal lobe atrophy is characteristic of AD) (69). Radiologists can conduct a quick and easy visual rating of any medial temporal lobe atrophy; these results can then be utilized by the specialist, in conjunction with a clinical assessment, to determine the likely cause of cognitive impairment. If the clinician is unable to determine a differential diagnosis, additional confirmatory tests can be requested.

Fluorodeoxyglucose-PET (FDG-PET) is a useful structural imaging biomarker that can support an early and differential diagnosis (72); however, specialists usually prefer to use this after their initial diagnostic work-up. As the brain relies almost exclusively on glucose as its source of energy, FDG (a glucose analog) can be combined with PET to identify regional patterns of reduced brain metabolism and neurodegeneration $(70,72)$. FDG-PET is not recommended for diagnosing patients with preclinical $\mathrm{AD}$, as there is no way to ascertain whether the hypometabolism is directly related to $\mathrm{AD}$ pathology (73); however, clinicians may refer patients with more established symptomatology for an FDG-PET 
scan to identify regions of glucose hypometabolism and neurodegeneration that could be indicative of $\mathrm{AD}(70)$.

\section{Case study: Assess/differentiate}

The initial assessment by the primary care clinician revealed that J.K.'s medical history was significant for hypertension, dyslipidemia, mild obesity, and glucose intolerance (Table 1B). There was no history of cerebrovascular events, significant head injuries, or focal findings on the neurologic exam. Besides the vascular risk factors, no medical conditions or current medications were found to be likely contributors to the cognitive deficit. The patient had a positive family history of dementia, where the onset typically occurred in the late 60 s. Genotyping showed the patient to be a homozygous carrier of two ApoE $\varepsilon 4$ alleles. Blood tests revealed elevated serum glucose and C-reactive protein but were otherwise normal. The patient had an unremarkable mental status examination, and his MoCA score was $21 / 30$, with points lost on orientation, recall, and naming (Table 1C).

The patient was referred to a memory clinic for further assessment. The dementia specialist referred the patient for an MRI that predominantly showed mild small vessel disease and mild generalized atrophy with a significant reduction in hippocampal volume and ratio. Based on his medical and family history, cognitive assessments, and structural imaging results, the specialist deemed the severity of cognitive impairment to be in the mild range; consequently, the specialist referred the patient for biomarker assessment to determine the underlying cause.

\section{Step 3: Diagnose}

Historically, AD was only diagnosed postmortem until we developed the ability to ascertain the underlying pathology associated with the disease in new ways, namely imaging and fluid biomarkers. However, despite supportive results from single- and multicenter trials, the use and reimbursement of imaging and fluid biomarkers to support the diagnosis of AD still vary considerably between countries (70).

\section{Imaging biomarkers}

Recent advances have allowed physicians to visualize the proteins associated with $A D$, namely $A \beta$ and tau, via PET scanning. Amyloid PET is currently the only imaging approach recommended by the Alzheimer's Association and the Amyloid Imaging Task Force to support the diagnosis of AD (70). Amyloid PET utilizes tracers (florbetapir, flutemetamol, and florbetaben) that specifically bind to $\mathrm{A} \beta$ within amyloid plaques; a positive amyloid PET scan will show increased cortical retention of the tracer in regions of $\mathrm{A} \beta$ deposition within the brain (74), thus confirming the presence of $\mathrm{A} \beta$ plaques in the brain $(74,75)$ and directly quantify brain amyloid pathology (76), thus making it a useful tool to supplement a clinical battery to diagnose $\operatorname{AD}(3,74)$. However, a positive amyloid PET scan alone does not definitively diagnose clinical $\mathrm{AD}$, and these results must be combined with other clinical assessments, such as cognitive assessment, for an accurate diagnosis (74). It is also important to note that amyloid PET is expensive and not readily reimbursed by health insurance providers (70); if it is not possible to access amyloid PET, biomarker confirmation can be assessed using CSF.

\section{Fluid biomarkers}

An additional or alternative tool to amyloid PET is the collection and analysis of CSF for the presence of biomarkers associated with AD pathology. Patients who have symptoms suggestive of $\mathrm{AD}$ can be referred for a lumbar puncture to analyze their CSF for specific AD-associated biomarkers (3). CSF biomarkers are measures of the concentrations of proteins in CSF from the lumbar sac that reflect the rates of both protein production and clearance at a given timepoint (7). Lumbar punctures can be conducted safely and routinely in an outpatient setting or memory clinic (77). However, many patients still worry about the pain and possible side effects associated with the procedure and may require additional information and support from the clinician to undertake the procedure (77). Appropriate use criteria are available for HCPs to help identify suitable patients for lumbar puncture and CSF testing (78). For example, individuals presenting with persistent, progressing, and unexplained MCI, or those with symptoms suggestive of possible $\mathrm{AD}$, should be referred for lumbar puncture and CSF testing (78). However, lumbar puncture and CSF testing are not recommended for determining disease severity in patients who have already received a diagnosis of $\mathrm{AD}$ or in lieu of genotyping for suspected autosomal dominant mutation carriers (78).

Because there is strong concordance between CSF biomarkers and amyloid PET, either can be used to confirm A $\beta$ burden (79). As such, CSF biomarkers are widely accepted within the AD community to support a diagnosis (80). AD biomarkers from the brain can be detected in CSF well before the onset of overt clinical symptoms in early-stage $\mathrm{AD}(6,7)$. Core $\mathrm{AD} C S F$ biomarkers, such as $A \beta 42$ (one of two main isoforms of $\mathrm{A} \beta$ and a major constituent of $\mathrm{A} \beta$ plaques) and phosphorylated tau (p-tau) and total tau (t-tau), can be measured to determine the presence of disease (80).

When interpreting CSF analyses for a patient with suspected $A D$, it is important to remember that $A D$ is associated with decreased CSF A $\beta 42$ and increased tau isoforms (32). Decreased CSF A $\beta 42$ levels are a reflection of increased $A \beta$ aggregation and deposition within the brain (32), and the concentration of CSF A $\beta 42$ directly relates to the patient's amyloid status (e.g., the presence 
or absence of significant amyloid pathology) and the total amount of $A \beta$ peptides (e.g., $A \beta 42$ and $A \beta 40$ ) (32). Specialists' use of ratios of these CSF biomarkers (e.g., A $\beta 42 / 40)$ rather than single CSF biomarkers alone has been shown to adjust for potential differences in $\mathrm{A} \beta$ production and provide a better index of the patient's underlying amyloid-related pathology (81). The increase in CSF p-tau and t-tau associated with AD may directly reflect the aggregation of tau within the brain and neurodegeneration, respectively (32). P-tau in CSF provides a direct measure of the amount of hyperphosphorylated tau in the brain, which is strongly suggestive of the presence of NFTs, whereas CSF t-tau can predict the level of neurodegeneration in a patient with suspected AD; however, $\mathrm{t}$-tau is also increased in other neurologic conditions (32).

Ultimately, the clinical decision to use amyloid PET or CSF to confirm amyloid and tau pathology can be affected by several practical factors (Table 5) $(70,77,80,82-85)$.

\section{Emerging diagnostic tools}

Access constraints for amyloid PET have driven the need for alternative sensitive and specific CSF and blood-based biomarkers that can detect AD-associated pathology in the early stages (86). Significant efforts have been undertaken over the last decade to identify blood-based biomarkers to: 1) detect AD pathology; 2) identify those at risk of developing $\mathrm{AD}$ in the future; and 3) monitor disease progression $(33,34,87)$. At present, only a limited number of approved blood-based assays are available to clinicians to detect AD pathology (88); however, several novel assays are currently under investigation, including those measuring various phosphorylated forms of tau, including p-tau181 and p-tau217 (89). Investigational use of plasma p-tau181 (an isoform of tau) has been shown to differentiate AD from other neurodegenerative diseases and predict cognitive decline in patients with AD (33). CSF p-tau217 (a different isoform of tau) is a promising biomarker under investigation for detecting preclinical and advanced $\mathrm{AD}(86,90)$. Given that blood testing is already a well-established part of clinical routines globally and can easily be performed in a variety of clinical settings, blood-based biomarkers could in future serve as the potential first step of a multistage diagnostic process. This would be a benefit to clinicians, particularly those in primary care, by helping to identify individuals requiring a referral to a specialist for diagnostic testing (87).

\section{Case study: Diagnose}

J.K. underwent a lumbar puncture for CSF analysis, which showed decreased A $\beta 42$ and increased p-tau and t-tau protein (Table 1D). Based on the results from the genotyping, cognitive assessments, MRI, and CSF biomarkers, the clinician confirmed that the likely cause of the patient's cognitive deficits was early-stage $\mathrm{AD}$, especially in view of a positive family history of dementia with similar age of onset.

\section{Step 4: Treat}

The role of the clinician following a diagnosis of early-stage $\mathrm{AD}$ is to discuss the available management and treatment options while providing emotional and practical support to the patient, caregiver, and family where appropriate (37). Clinicians can also refer the patient and their caregiver(s) to social services for further support, as well as help connect them with reliable sources of information and even local research opportunities and clinical trials.

One important role for a clinician treating a patient diagnosed with early-stage $\mathrm{AD}$ is to closely monitor the patient's disease progression through regular follow-up appointments (e.g., every 6-12 months); clinicians should encourage patients (and the caregiver) to make additional follow-up appointments, especially should symptoms worsen. Routine cognitive and functional assessments (Table 4) should be used to monitor disease progression; these tools can be used to identify unexpected trends, such as rapid decline, which could prompt the need for additional medical evaluation such as blood tests, imaging, or biomarker analyses. Results from such tests could help guide management and/or treatment decisions over the course of the patient's disease.

Non-pharmacologic therapies (e.g., diet and exercise) may be employed for patients with early $A D$, with the goal to maintain or even improve cognitive function and retain their ability to perform activities of daily living. For patients in the early stages of disease, dietary changes (e.g., following a healthy diet high in green, leafy vegetables, fish, nuts, and berries), physical exercise, and cognitive training have demonstrated small but significant improvements in cognition $(36,91)$. Nonpharmacologic therapies can have a positive impact on quality of life and are generally safe and inexpensive (36); however, compliance with these non-pharmacologic therapies should be monitored by the clinician. Research suggests that multimodal therapies, such as cognitive stimulation therapy, may also be more effective when used in combination with pharmacologic treatments (91).

Several pharmacologic treatments have received regulatory approval to treat the symptoms of mild to severe AD dementia. Acetylcholinesterase inhibitors (donepezil, rivastigmine, and galantamine) and $\mathrm{N}$-methyl-D-aspartate receptor antagonists (memantine) can be prescribed to patients to temporarily ameliorate the symptoms of AD dementia such as cognitive and functional decline (92-96). Meta-analyses of donepezil, rivastigmine, and galantamine have shown that patients with mild-to-moderate AD dementia experience some benefits in cognitive function, activities of daily living, and clinician-rated global clinical state (93, 94, 
97). Furthermore, treatment with acetylcholinesterase inhibitors and/or memantine has also been shown to modestly improve measures of global function and temporarily stabilize measures of activities of daily living (96). However, it is important to note that these drugs provide only temporary, symptomatic benefit and that not all patients respond to treatment $(36,98)$. Critically, none of the current drugs available address the underlying pathophysiology or alter the ultimate disease course.

Following AD diagnosis, a comprehensive approach toward clinical care can be individualized based on the patient's specific AD risk factors $(20,21)$. Clinicians should consider managing uncontrolled vascular risk factors (e.g., hypertension, hyperlipidemia, diabetes) with antithrombotics, antihypertensives, lipid-lowering, and/ or antidiabetic agents, respectively, to reduce the risk of cerebrovascular ischemia and stroke, and subsequent cognitive decline $(36,99)$. They should also consider the management of the patient's behavioral symptoms. For most patients in the early stages of disease, behavioral symptoms will be relatively mild, and no pharmacologic management is required; however, pharmacologic treatment, such as a low-dose selective serotonin reuptake inhibitor, can be prescribed for patients with AD-associated depression and anxiety $(100,101)$.

\section{Specialist clinician checklist}

The specialist's role is critical to further evaluating the initial checks/assessments, providing the diagnosis, and developing the individualized patient management plan:

- Identify deficits to specific cognitive domains using appropriate tests

- Confirm functional performance, using patient and caregiver assessments

- Perform structural imaging to complete assessment of the patient

- Confirm diagnosis with imaging or fluid biomarkers

- Develop a personalized management and follow-up plan

- Direct the patient to additional support resources such as the Alzheimer's Association

\section{Case study: Treat}

Following diagnosis, J.K. was advised on the available management options and research opportunities (Table $1 \mathrm{E})$. The specialist emphasized the need to control his vascular risk factors and suggested lifestyle modifications to optimize the management of his other medical problems. The patient's neuropsychiatric symptoms were considered mild and did not require pharmacologic intervention. The patient was also provided with details for a local social worker and directed toward further disease-specific information from the Alzheimer's Association related to his disease. The patient was encouraged to return for additional follow-up visits so that his disease and associated symptoms could be appropriately monitored and managed.

\section{Future perspectives}

An early diagnosis of AD will become increasingly important as treatments that alter the underlying disease pathology become available-particularly given the expectation that such treatments will be more effective in preserving cognitive function, and thus prolonging independence, when given early in the course of the disease (19). The approval of such treatments will likely lead to an increased awareness of cognitive impairment and other AD-associated symptoms among both the public and non-specialists, such as those in primary care settings. This may encourage more patients/family members to seek help at an earlier stage of disease than is currently seen in community practice. Increased use of sensitive screening measures to proactively assess for the presence of AD symptoms will help identify patients suspected of having early AD. Assessment of cognitive impairment during a Medicare Annual Wellness Visit is inconsistent; the U.S. Preventative Services Task Force, whilst recognizing the importance of MCI, has maintained its decision that there is insufficient evidence to support the mandate of cognitive screening. However, sensitive screening procedures, along with the availability of disease-modifying treatments, are likely to change their recommendations. There is also a need for a mandated, standardized screening approach internationally. Together, this will result in an increase in patients requiring diagnosis, increasing the demand for specialists to evaluate and diagnose, the need for amyloid confirmation, and wait times for patients, which will collectively put further pressure on an already-stretched healthcare infrastructure (25).

Nevertheless, efforts continue within the AD field to streamline the diagnostic process. Planning for and implementing change will not only improve patient management now but also help prepare healthcare systems for an approved disease-modifying treatment for AD. A flexible, multidisciplinary team approach is recommended to integrate the care needed to detect, assess, differentiate, diagnose, treat, and monitor a diverse AD population (24). The development of tests that could be carried out routinely in a primary care setting, such as blood-based AD biomarkers, would help PCPs and non-specialists identify which patients may need further evaluation or referral to a specialist (25). Interest also remains high in advancing imaging techniques, such as amyloid and tau PET, to support a diagnosis of AD. Although amyloid and tau PET are not currently readily available, they may be useful for specialists in the future to determine disease staging or track progression, or as a surrogate marker of cognitive status (74). The introduction of new screening and diagnostic tools could ultimately help lower the burden on specialists and 
ensure patients are diagnosed in a timely manner.

\section{Conclusions}

Consensus within the AD community has recently shifted to encourage the diagnosis of AD as early as possible. This shift will enable patients to plan their future and consider symptomatic therapies and lifestyle changes that could reduce cognitive deficits and ultimately help preserve their quality of life. Promisingly, new, potentially disease-modifying therapeutic candidates are on the horizon that could be effective in early $\mathrm{AD}$ by targeting and ameliorating the underlying biological mechanisms $(92,102)$. This paper has outlined a menu of practical tools for clinicians to use in the real world to support an early diagnosis of $\mathrm{AD}$ and how they may best be incorporated into current clinical practice. Ultimately, a coordinated, multidisciplinary approach that encompasses primary care and specialist expertise is required to ensure timely detection, assessment and differentiation, diagnosis, and management of patients with AD.

Authors' contributions: All authors participated in the review of the literature and in the drafting and reviewing of the manuscript. All authors read and approved the final version of the manuscript for submission.

Funding: The authors developed this manuscript concept during an assessment of Alzheimer's disease educational needs. The development of this manuscript was funded by Biogen. Editorial support was provided by Jodie Penney, MSc, PhD, Helios Medical Communications, Cheshire, UK, which was funded by Biogen.

Acknowledgements: The authors would like to acknowledge and thank Dr. Giovanni Frisoni, Geneva University Neurocenter, for his contribution towards the development of this manuscript.

Conflict of Interest: AP reports personal fees from Acadia Pharmaceuticals, Alzheon, Avanir, Biogen, Cadent Therapeutics, Eisai, Functional Neuromodulation, MapLight Therapeutics, Premier Healthcare Solutions, Sunovion, and Syneos; grants from Alector, Athira, Avanir, Biogen, Biohaven, Eisai, Eli Lilly, Genentech/ Roche, and Vaccinex. RI has nothing to disclose. MS reports personal fees from Alzheon, Athira, Biogen, Cortexyme, Danone, Neurotrope, Regeneron, RocheGenentech, and Stage 2 Innovations; stock options from Brain Health Inc, NeuroReserve, NeuroTau, Neurotrope, Optimal Cognitive Health Company, uMethod Health, and Versanum Inc. Additionally, he has intellectual property rights with Harper Collins. SK and IR report employment with Biogen.

Electronic supplementary material: Practical Guidance extender video.

Open Access: This article is distributed under the terms of the Creative Commons Attribution 4.0 International License (http:/ / creativecommons.org/ licenses/by/4.0/), which permits use, duplication, adaptation, distribution and reproduction in any medium or format, as long as you give appropriate credit to the original author(s) and the source, provide a link to the Creative Commons license and indicate if changes were made.

\section{References}

1. Hughes J. This is one of the biggest global health crises of the 21st century. World Econ Forum 2017. https: / www.weforum.org/agenda/2017/09/ dementia-trillion-dollar-global-crisis / \#: : text=This $\% 20$ World $\% 20$ Alzheimer's\%20Day\%2C\%20the,crises $\% 20$ of $\% 20$ the $\% 2021$ st $\% 20$ century (accessed May 18, 2020).

2. Alzheimer's Disease International. World Alzheimer Report 2019. Attitudes to dementia 2019. https:/ / www.alz.co.uk/ research/WorldAlzheimerReport2019. pdf (accessed February 13, 2020).

3. Alzheimer's Association. 2020 Alzheimer's disease facts and figures. Alzheimers Dement 2020;16:391-460.

4. Deb A, Thornton JD, Sambamoorthi U, Innes K. Direct and indirect cost of managing alzheimer's disease and related dementias in the United States. Expert Rev Pharmacoecon Outcomes Res 2017;17:189-202.

5. Serrano-Pozo A, Frosch MP, Masliah E, Hyman BT. Neuropathological alterations in Alzheimer disease. Cold Spring Harb Perspect Med 2011;1:a006189.

6. Bateman RJ, Xiong C, Benzinger TL, et al. Clinical and biomarker changes in dominantly inherited Alzheimer's disease. N Engl J Med 2012;367:795-804.

7. Jack CR, Bennett DA, Blennow K, et al. NIA-AA Research Framework: toward a biological definition of Alzheimer's disease. Alzheimers Dement 2018;14:535-62.

8. Dubois B, Feldman HH, Jacova C, et al. Revising the definition of Alzheimer's disease: a new lexicon. Lancet Neurol 2010;9:1118-27.

9. U.S. Food and Drug Administration (FDA). Early Alzheimer's disease: developing drugs for treatment guidance for industry 2018. https:/ / www.fda. gov/regulatory-information/search-fda-guidance-documents/alzheimersdisease-developing-drugs-treatment-guidance-industy (accessed August 11, 2020).

10. Insel PS, Weiner M, Mackin RS, et al. Determining clinically meaningful decline in preclinical Alzheimer disease. Neurology 2019;93:e322-33.

11. Vermunt L, Sikkes SA, van den Hout A, et al. Duration of preclinical, prodromal, and dementia stages of Alzheimer's disease in relation to age, sex, and APOE genotype. Alzheimers Dement 2019;15:888-98.

12. Cho SH, Woo S, Kim C, et al. Disease progression modelling from preclinical Alzheimer's disease (AD) to AD dementia. Sci Rep 2021;11:4168.

13. Knopman DS, Parisi JE, Salviati A, et al. Neuropathology of cognitively normal elderly. J Neuropathol Exp Neurol 2003;62:1087-95.

14. Bennett DA, Schneider JA, Arvanitakis Z, et al. Neuropathology of older persons without cognitive impairment from two community-based studies. Neurology 2006;66:1837-44.

15. Kazim SF, Iqbal K. Neurotrophic factor small-molecule mimetics mediated neuroregeneration and synaptic repair: emerging therapeutic modality for Alzheimer's disease. Mol Neurodegener 2016;11:50.

16. Tolbert S, Liu $\mathrm{Y}$, Hellegers $\mathrm{C}$, et al. Financial management skills in aging, $\mathrm{MCI}$ and dementia: cross sectional relationship to 18F-florbetapir PET cortical $\beta$-amyloid deposition. J Prev Alzheimers Dis 2019;6:274-82.

17. Ye BS, Kim HJ, Kim YJ, et al. Longitudinal outcomes of amyloid positive versus negative amnestic mild cognitive impairments: a three-year longitudinal study. Sci Rep 2018;8:5557.

18. Roberts RO, Aakre JA, Kremers WK, et al. Prevalence and outcomes of amyloid positivity among persons without dementia in a longitudinal, population-based setting. JAMA Neurol 2018;75:970-9.

19. Dubois B, Padovani A, Scheltens P, Rossi A, Dell'Agnello G. Timely diagnosis for Alzheimer's disease: a literature review on benefits and challenges. J Alzheimers Dis 2016;49:617-31.

20. Isaacson RS, Ganzer CA, Hristov $\mathrm{H}$, et al. The clinical practice of risk reduction for Alzheimer's disease: a precision medicine approach. Alzheimers Dement 2018;14:1663-73.

21. Isaacson RS, Hristov $\mathrm{H}$, Saif $\mathrm{N}$, et al. Individualized clinical management of patients at risk for Alzheimer's dementia. Alzheimers Dement 2019;15:1588602.

22. Gauthier SG. Alzheimer's disease: the benefits of early treatment. Eur J Neurol 2005;12:11-6.

23. Cummings J, Lee G, Ritter A, Sabbagh M, Zhong K. Alzheimer's disease drug development pipeline: 2020. Alzheimers Dement NY 2020;6:e12050.

24. Galvin JE, Aisen P, Langbaum JB, et al. Early stages of Alzheimer's disease: evolving the care team for optimal patient management. Front Neurol 2021;11:592302.

25. Liu JL, Hlavka JP, Hillestad R, Mattke S. Assessing the preparedness of the U.S. Health Care System infrastructure for an Alzheimer's treatment 2017. https:/ / www.rand.org/pubs/research_reports/RR2272.html (accessed May 5, 2018).

26. Sabbagh MN, Lue L-F, Fayard D, Shi J. Increasing precision of clinical diagnosis of Alzheimer's disease using a combined algorithm incorporating clinical and novel biomarker data. Neurol Ther 2017;6:83-95.

27. Balasa M, Gelpi E, Antonell A, et al. Clinical features and APOE genotype of pathologically proven early-onset Alzheimer disease. Neurology 2011;76:1720 5 .

28. Galvin JE. Using informant and performance screening methods to detect mild cognitive impairment and dementia. Curr Geriatr Rep 2018;7:19-25.

29. Sabbagh MN, Boada M, Borson S, et al. Early detection of mild cognitive impairment (MCI) in primary care. J Prev Alzheimers Dis 2020;7:165-70.

30. Galvin JE, Sadowsky CH, NINCDS-ADRDA. Practical guidelines for the recognition and diagnosis of dementia. J Am Board Fam Med 2012;25:367-82.

31. Aisen PS, Cummings J, Jack CR, et al. On the path to 2025: understanding the Alzheimer's disease continuum. Alzheimers Res Ther 2017;9:60.

32. Blennow K, Zetterberg H. Biomarkers for Alzheimer disease - current status and prospects for the future. J Intern Med 2018;284:643-63.

33. Karikari TK, Pascoal TA, Ashton NJ, et al. Blood phosphorylated tau 181 as a biomarker for Alzheimer's disease: a diagnostic performance and prediction modelling study using data from four prospective cohorts. Lancet Neurol 2020;19:422-33. 
34. Janelidze S, Mattsson N, Palmqvist S, et al. Plasma P-tau181 in Alzheimer's disease: relationship to other biomarkers, differential diagnosis, neuropathology and longitudinal progression to Alzheimer's dementia. Nat Med 2020;26:379-86

35. Iliffe S, Robinson L, Brayne C, et al. Primary care and dementia: 1. diagnosis, screening and disclosure. Int J Geriatr Psychiatry 2009;24:895-901.

36. Arvanitakis Z, Shah RC, Bennett DA. Diagnosis and management of dementia: review. JAMA 2019;322:1589-99.

37. Robinson L, Tang E, Taylor J-P. Dementia: timely diagnosis and early intervention. BMJ 2015;350:h3029.

38. Zucchella C, Bartolo M, Pasotti C, Chiapella L, Sinforiani E. Caregiver burden and coping in early-stage Alzheimer disease. Alzheimer Dis Assoc Disord 2012;26:55-60.

39. Pfistermeister B, Tümena $T$, Gaßmann K-G, Maas R, Fromm MF. Anticholinergic burden and cognitive function in a large German cohort of hospitalized geriatric patients. PLoS One 2017;12:e171353.

40. Liu C-C, Liu C-C, Kanekiyo T, Xu H, Bu G. Apolipoprotein E and Alzheimer disease: risk, mechanisms, and therapy. Nat Rev Neurol 2013;9:106-18.

41. Sadigh-Eteghad S, Sabermarouf B, Majdi A, Talebi M, Farhoudi M, Mahmoudi J. Amyloid-beta: a crucial factor in Alzheimer's disease. Med Princ Pract 2015;24:1-10.

42. Karch CM, Goate AM. Alzheimer's disease risk genes and mechanisms of disease pathogenesis. Biol Psychiatry 2015;77:43-51.

43. Ungar L, Altmann A, Greicius MD. Apolipoprotein E, gender, and Alzheimer's disease: an overlooked, but potent and promising interaction. Brain Imaging Behav 2014;8:262-73.

44. 23andMe. What to know about health report test result - 23andMe. $23 \& \mathrm{Me}{ }^{\circledR}$ 2020. https:/ / www.23andme.com/test-info/ (accessed October 15, 2020).

45. Hendry K, Green C, McShane R, et al. AD-8 for detection of dementia across a variety of healthcare settings. Cochrane Database Syst Rev 2019;3:CD011121.

46. Patnode CD, Perdue LA, Rossom RC, et al. Screening for cognitive impairment in older adults: an evidence update for the U.S. Preventive Services Task Force. Rockville (MD): Agency for Healthcare Research and Quality (US); Report No. 19-05257-EF-1, 2020.

47. Teng E, Becker BW, Woo E, Cummings JL, Lu PH. Subtle deficits in instrumental activities of daily living in subtypes of mild cognitive impairment. Dement Geriatr Cogn Disord 2010;30:189-97.

48. Marshall GA, Amariglio RE, Sperling RA, Rentz DM. Activities of daily living: where do they fit in the diagnosis of Alzheimer's disease? Neurodegener Dis Manag 2012;2:483-91.

49. Rosenberg PB, Mielke MM, Appleby BS, Oh ES, Geda YE, Lyketsos CG. The association of neuropsychiatric symptoms in MCI with incident dementia and Alzheimer disease. Am J Geriatr Psychiatry 2013;21:685-95.

50. Ismail Z, Emeremni CA, Houck PR, et al. A comparison of the E-BEHAVE$\mathrm{AD}, \mathrm{NBRS}$ and NPI in quantifying clinical improvement in the treatment of agitation and psychosis associated with dementia. Am J Geriatr Psychiatry 2013;21:78-87.

51. Bowden VM, Bowden CL. The Journal of Neuropsychiatry and Clinical Neurosciences. JAMA 1992;268:1473-4.

52. Galvin JE. The quick dementia rating system (QDRS): a rapid dementia staging tool. Alzheimers Dement Amst 2015;1:249-59.

53. Koster N, Knol DL, Uitdehaag BM, Scheltens P, Sikkes SA. The sensitivity to change over time of the Amsterdam IADL Questionnaire(C). Alzheimers Dement 2015;11:1231-40.

54. Sikkes SA, Pijnenburg YA, Knol DL, de Lange-de Klerk ES, Scheltens P, Uitdehaag BM. Assessment of instrumental activities of daily living in dementia: diagnostic value of the Amsterdam Instrumental Activities of Daily Living Questionnaire. J Geriatr Psychiatry Neurol 2013;26:244-50.

55. LaRue RH. Functional Assessment Screening Tool (FAST). In: Volkmar FR editor. Encycl. Autism Spectr. Disord., New York, NY: Springer New York, 2018:1-2.

56. Lindgren N, Rinne JO, Palviainen T, Kaprio J, Vuoksimaa E. Prevalence and correlates of dementia and mild cognitive impairment classified with different versions of the modified Telephone Interview for Cognitive Status (TICS-m). Int J Geriatr Psychiatry 2019;34:1883-91.

57. Wang H, Fan Z, Shi C, et al. Consensus statement on the neurocognitive outcomes for early detection of mild cognitive impairment and Alzheimer dementia from the Chinese Neuropsychological Normative (CN-NORM) Project. J Glob Health 2019;9:020320.

58. Franzen S, van den Berg E, Goudsmit M, et al. A systematic review of neuropsychological tests for the assessment of dementia in non-western, loweducated or illiterate populations. J Int Neuropsychol Soc 2020;26:331-51.

59. Costa A, Bak T, Caffarra P, et al. The need for harmonisation and innovation of neuropsychological assessment in neurodegenerative dementias in Europe: consensus document of the Joint Program for Neurodegenerative Diseases Working Group. Alzheimers Res Ther 2017;9:27.

60. MoCA Test Inc. Upcoming mandatory training for MoCA testing. MoCA
Montr - Cogn Assess 2021. https: / / www.mocatest.org/mandatory-moca-testtraining/ (accessed February 3, 2021).

61. Tabira T, Hotta M, Murata M, et al. Age-related changes in instrumental and basic activities of daily living impairment in older adults with very mild Alzheimer's disease. Dement Geriatr Cogn Disord Extra 2020;10:27-37.

62. Martyr A, Nelis SM, Quinn C, et al. The relationship between perceived functional difficulties and the ability to live well with mild-to-moderate dementia: findings from the IDEAL programme. Int J Geriatr Psychiatry 2019;34:1251-61.

63. Ismail Z, Smith EE, Geda Y, et al. Neuropsychiatric symptoms as early manifestations of emergent dementia: provisional diagnostic criteria for mild behavioral impairment. Alzheimers Dement 2016;12:195-202.

64. McAllister-Williams RH, Bones K, Goodwin GM, et al. Analysing UK clinicians' understanding of cognitive symptoms in major depression: a survey of primary care physicians and psychiatrists. J Affect Disord 2017;207:346-52.

65. Richard E, Schmand B, Eikelenboom P, Yang SC, Ligthart SA. Symptoms of apathy are associated with progression from mild cognitive impairment to Alzheimers disease in non-depressed subjects. Dement Geriatr Cogn Disord 2012;33:204-9.

66. Weintraub S, Besser L, Dodge HH, et al. Version 3 of the Alzheimer Disease Centers' Neuropsychological Test Battery in the Uniform Data Set (UDS). Alzheimer Dis Assoc Disord 2018;32:10-7.

67. Harrison JE, Hendrix S. Chapter 21 - The assessment of cognition in translational medicine: a contrast between the approaches used in Alzheimer's disease and major depressive disorder. In: Nomikos GG, Feltner DE, editors. Handb. Behav. Neurosci., vol. 29, Elsevier, 2019:297-308.

68. Roberts R, Knopman DS. Classification and epidemiology of MCI. Clin Geriatr Med 2013;29:753-72.

69. Harper L, Barkhof F, Scheltens P, Schott JM, Fox NC. An algorithmic approach to structural imaging in dementia. J Neurol Neurosurg Psychiatry 2014;85:6928

70. Frisoni GB, Boccardi M, Barkhof F, et al. Strategic roadmap for an early diagnosis of Alzheimer's disease based on biomarkers. Lancet Neurol 2017;16:661-76.

71. Dubois B, Feldman HH, Jacova C, et al. Advancing research diagnostic criteria for Alzheimer's disease: the IWG-2 criteria. Lancet Neurol 2014;13:614-29.

72. Johnson KA, Fox NC, Sperling RA, Klunk WE. Brain imaging in Alzheimer disease. Cold Spring Harb Perspect Med 2012;2:a006213.

73. Dubois B, Hampel H, Feldman HH, et al. Preclinical Alzheimer's disease: definition, natural history, and diagnostic criteria. Alzheimers Dement 2016;12:292-323.

74. Villemagne VL, Doré V, Burnham SC, Masters CL, Rowe CC. Imaging tau and amyloid- $\beta$ proteinopathies in Alzheimer disease and other conditions. Nat Rev Neurol 2018;14:225-36.

75. Clark CM, Pontecorvo MJ, Beach TG, et al. Cerebral PET with florbetapir compared with neuropathology at autopsy for detection of neuritic amyloid- $\beta$ plaques: a prospective cohort study. Lancet Neurol 2012;11:669-78.

76. Wong DF, Rosenberg PB, Zhou Y, et al. In vivo imaging of amyloid deposition in Alzheimer disease using the radioligand 18F-AV-45 (florbetapir F 18). J Nucl Med 2010;51:913-20.

77. Duits FH, Martinez-Lage P, Paquet C, et al. Performance and complications of lumbar puncture in memory clinics: results of the multicenter lumbar puncture feasibility study. Alzheimers Dement 2016;12:154-63.

78. Shaw LM, Arias J, Blennow K, et al. Appropriate use criteria for lumbar puncture and cerebrospinal fluid testing in the diagnosis of Alzheimer's disease. Alzheimers Dement 2018;14:1505-21.

79. Hansson O, Seibyl J, Stomrud E, et al. CSF biomarkers of Alzheimer's disease concord with amyloid- $\beta$ PET and predict clinical progression: a study of fully automated immunoassays in BioFINDER and ADNI cohorts. Alzheimers Dement 2018;14:1470-81.

80. Blennow K, Dubois B, Fagan AM, Lewczuk P, de Leon MJ, Hampel H. Clinical utility of cerebrospinal fluid biomarkers in the diagnosis of early Alzheimer's disease. Alzheimers Dement 2015;11:58-69.

81. Hansson O, Lehmann S, Otto M, Zetterberg H, Lewczuk P. Advantages and disadvantages of the use of the CSF Amyloid $\beta$ (A $\beta$ ) 42/40 ratio in the diagnosis of Alzheimer's Disease. Alzheimers Res Ther 2019;11:34.

82. Lee SA, Sposato LA, Hachinski V, Cipriano LE. Cost-effectiveness of cerebrospinal biomarkers for the diagnosis of Alzheimer's disease. Alzheimers Res Ther 2017;9:18.

83. Dolgin E. Alzheimer's disease is getting easier to spot. Nature 2018;559:S10-2.

84. Morris E, Chalkidou A, Hammers A, Peacock J, Summers J, Keevil S. Diagnostic accuracy of $18 \mathrm{~F}$ amyloid PET tracers for the diagnosis of Alzheimer's disease: a systematic review and meta-analysis. Eur J Nucl Med Mol Imaging 2016;43:374-85.

85. Engelborghs S, Niemantsverdriet E, Struyfs H, et al. Consensus guidelines for lumbar puncture in patients with neurological diseases. Alzheimers Dement Amst 2017;8:111-26. 
86. Barthélemy NR, Bateman RJ, Hirtz C, et al. Cerebrospinal fluid phosphotau T217 outperforms T181 as a biomarker for the differential diagnosis of Alzheimer's disease and PET amyloid-positive patient identification. Alzheimers Res Ther 2020;12:26.

87. O'Bryant SE, Mielke MM, Rissman RA, et al. Blood-based biomarkers in Alzheimer disease: current state of the science and a novel collaborative paradigm for advancing from discovery to clinic. Alzheimers Dement 2017; 13:45-58.

88. C2N Diagnostics. Press release. Alzheimer's breakthrough: $\mathrm{C}_{2} \mathrm{~N}$ first to offer a widely accessible blood test. C2N Diagn 2021. https:/ / www.c2ndiagnostics. $\mathrm{com} /$ press / press / 2020 / 10 / 28/alzheimers-breakthrough-cn-first-to-offer-awidely-accessible-blood-test (accessed January 25, 2021).

89. Barthélemy NR, Horie K, Sato C, Bateman RJ. Blood plasma phosphorylatedtau isoforms track CNS change in Alzheimer's disease. J Exp Med 2020;217:e20200861.

90. Janelidze S, Stomrud E, Smith R, et al. Cerebrospinal fluid p-tau217 performs better than p-tau181 as a biomarker of Alzheimer's disease. Nat Commun 2020;11:1683.

91. Chen J, Duan Y, Li H, Lu L, Liu J, Tang C. Different durations of cognitive stimulation therapy for Alzheimer's disease: a systematic review and metaanalysis. Clin Interv Aging 2019;14:1243-54.

92. Cummings J, Fox N. Defining disease modifying therapy for Alzheimer's disease. J Prev Alzheimers Dis 2017;4:109-15.

93. Birks JS, Harvey RJ. Donepezil for dementia due to Alzheimer's disease. Cochrane Database Syst Rev 2018;6:CD001190

94. Birks JS, Chong LY, Grimley Evans J. Rivastigmine for Alzheimer's disease. Cochrane Database Syst Rev 2015;9:CD001191.

95. Tariot PN, Farlow MR, Grossberg GT, et al. Memantine treatment in patients with moderate to severe Alzheimer disease already receiving donepezil: a randomized controlled trial. JAMA 2004;291:317-24.

96. Cummings J. New approaches to symptomatic treatments for Alzheimer's disease. Mol Neurodegener 2021;16:2.

97. Loy C, Schneider L. Galantamine for Alzheimer's disease and mild cognitive impairment. Cochrane Database Syst Rev 2006;1:CD001747.

98. Atri A. The Alzheimer's Disease Clinical Spectrum. Med Clin N Am 2019;103:263-93.

99. Berlowitz DR, Foy CG, Kazis LE, et al. Effect of intensive blood-pressure treatment on patient-reported outcomes. N Engl J Med 2017;377:733-44.

100. Porsteinsson AP, Drye LT, Pollock BG, et al. Effect of citalopram on agitation in Alzheimer's disease - the citAD randomized controlled trial. JAMA 2014;311:682-91.
101. Sheline YI, Snider BJ, Beer JC, et al. Effect of escitalopram dose and treatment duration on CSF A $\beta$ levels in healthy older adults: a controlled clinical trial. Neurology 2020;95:e2658-65.

102. Sheehan B. Assessment scales in dementia. Ther Adv Neurol Disord 2012;5:349-58.

103. Haubois G, Annweiler C, Launay C, et al. Development of a short form of Mini-Mental State Examination for the screening of dementia in older adults with a memory complaint: a case control study. BMC Geriatr 2011;11:59.

104. Horton DK, Hynan LS, Lacritz LH, Rossetti HC, Weiner MF, Cullum CM. An Abbreviated Montreal Cognitive Assessment (MoCA) for dementia screening. Clin Neuropsychol 2015;29:413-25.

105. Mini-Cog( $\odot$. Mini-Cog( In other languages. Mini-Cog® Lang 2021. https:// mini-cog.com/mini-cog-in-other-languages / (accessed April 21, 2021).

106. Carnero Pardo C, de la Vega Cotarelo R, López Alcalde S, et al. Assessing the diagnostic accuracy (DA) of the Spanish version of the informant-based AD8 questionnaire. Neurologia 2013;28:88-94.

107. Harrison JK, Fearon P, Noel-Storr AH, McShane R, Stott DJ, Quinn TJ. Informant questionnaire on cognitive decline in the elderly (IQCODE) for the diagnosis of dementia within a secondary care setting. Cochrane Database Syst Rev 2015;3:CD010772.

108. Sanchez MA, Correa PC, Lourenço RA. Cross-cultural adaptation of the "Functional Activities Questionnaire - FAQ" for use in Brazil. Dement Neuropsychol 2011;5:322-7.

109. Kim G, DeCoster J, Huang C-H, Bryant AN. A meta-analysis of the factor structure of the Geriatric Depression Scale (GDS): the effects of language. In Psychogeriatr 2013;25:71-81.

110. Mapi Research Trust. NPI - Officially distributed by Mapi Research Trust. Neuropsychiatr Inventory Quest NPI-Q 2021. https: / / eprovide.mapi-trust. org/instruments/neuropsychiatric-inventory-questionnaire (accessed April 21, 2021).

111. Mapi Research Trust. A-IADL-Q-SV - Amsterdam Instrumental Activity of Daily Living Questionnaire - Short version. Amst Instrum Act Dly Living Quest - Short Version -IADL-Q-SV n.d. https: / / eprovide.mapi-trust.org/ instruments / amsterdam-instrumental-activity-of-daily-living-questionnaireshort-version (accessed April 21, 2021).

112. Ismail Z, Agüera-Ortiz L, Brodaty H, et al. The Mild Behavioral Impairment Checklist (MBI-C): a rating scale for neuropsychiatric symptoms in predementia populations. J Alzheimers Dis 2017;56:929-38. 